\title{
Finite Element Modeling of Fatigue Life of Steel Wire
}

\author{
Hanaa M. Lotfy ${ }^{* 1}$, Adel B. El-Shabasy ${ }^{* 2}$, Tayseer A. Attia ${ }^{\star 3}$, and \\ Hala A. Hassan ${ }^{\star 2}$
}

\section{${ }^{*}$ Dept. of Design and Production Engineering, Faculty of Engineering, Ain Shams University}

\author{
${ }^{1}$ M.Sc. Student, ${ }^{2}$ Professor, ${ }^{3}$ Associate Professor
}

\begin{abstract}
In this work, bending fatigue life of steel wire has been studied using finite element modeling by ANSYS program. To verify the finite element results; a fatigue setup was designed and constructed, and the wire was tested using this setup. The results showed that the fatigue life of the wire that bent over the smaller bending diameter has the lower fatigue life, while increasing the bending diameter has a great effect on increasing the fatigue life of steel wire. The finite element results were almost near the experimental results with an accepted percent of deviation. The other values such as, equivalent (Von-Mises) stress, elastic strain, plastic strain, total strain, and the total deformation were estimated using finite element modeling. The Von-Mises parameters results showed that the wire bent over the bigger bending diameter has the lower values in which affect its fatigue life in a positive way.
\end{abstract}

\section{Key words}

Finite Element Method, steel wire, modeling, and bending fatigue life.

\section{Introduction}

Many applications in different fields use wire ropes as very essential parts to make these applications get their function done properly. Such applications include bridges, cranes, elevators, and so on [1-3]. Because of the importance of wire ropes; various studies were conducted to estimate their mechanical properties under different circumstances and then enhance them to gain the optimum specifications that best fit their applications. Other studies were done to get better understanding of their behavior during the operating period. Some researchers studied the different types of faults, their causes, how they affect the performance of the wire ropes. Researchers like Juan $\mathrm{Wu}$ [4]; studied the mechanical properties of the wire rope under tension using FEM. The results were compared with theoretical and experimental results. Also, Gerdemeli, Kurt S., and Anıl A.S. [5], used FEM to estimate the fatigue life of one simple strand by applying axial force and using different parameters such as, force, helix angle and length of the strand. Sung-Yun Kim and Phill-Seung Lee [6], used the Finite Element Modeling to get the mechanical 
behavior of the wire rope under the effect of both axial and transverse types of loadings. Then, they compared their results to those of numerical analyzing and experimental tests. Consequently, these several approaches to inspect the wire ropes are used to ensure keeping acceptable level of effectiveness operating.

To study the wire rope; it is important to know its construction. Most of wire ropes consist of three main parts; wires, strands, and core, Figure 1. Wires are the main part of the wire ropes in which a group of them helically twisted to form the strands. A group of strands helically twisted around the core to form the final shape of the wire rope [6]. It is important to study the mechanical properties of the wires separately as they are the foundation stone of the wire rope.

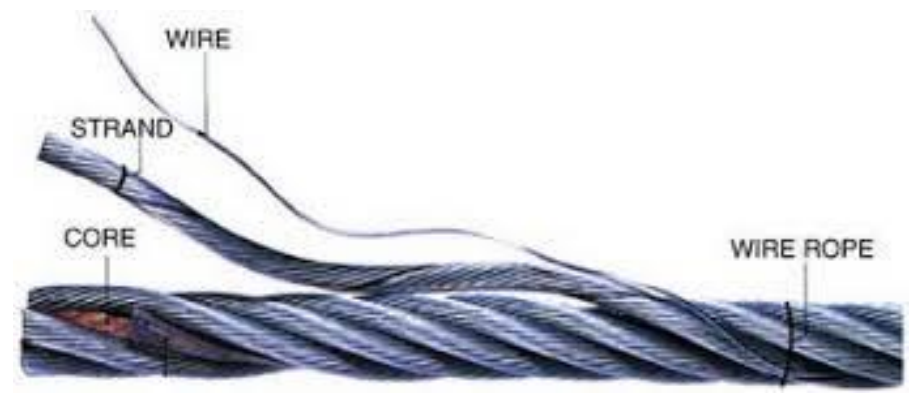

Fig.1. Wire rope construction [6].

Tests such as tension and fatigue are the most common types of tests that can be used for wire rope evaluation [7-8]. Finite element modeling has been used in this work to estimate the fatigue life of steel wire. In addition, some other mechanical characteristics could be obtained. FE modeling is based on dividing any object into very tiny parts called elements, and then each element can be studied separately to determine the applied forces, displacements and other internal and external factors that could affect its mechanical properties [9-12].

By solving the stiffness matrix [1]; it became available to obtain the required properties.

$\{\mathrm{F}\}=[\mathrm{K}] *\{\mathrm{U}\}$.

Where, $\{F\}$ is the applied forces array,

$[\mathrm{K}]$ is the stiffness matrix, and

$\{U\}$ is the displacement array.

\section{Experimental work}

Experiments were conducted using a fatigue setup that was designed and constructed to get the fatigue life of structural steel wire similar to that used in elevators wire ropes. Its concept is similar to that of the elevators and based on 
bending the wire around two pulleys one of them is the drive pulley which is connected to the motor as shown in Figure 2. The other is the driven one which transmitted the rotational force from the friction between the wire and the drive pulley which makes the wire move around the driven pulley. Because of the effect of friction, the driven pulley moves. The two terminals of the wire were held by the movable indicator. Other two fixed indicators were used to limit the start and the end of the stroke of the wire with the movable indicator.

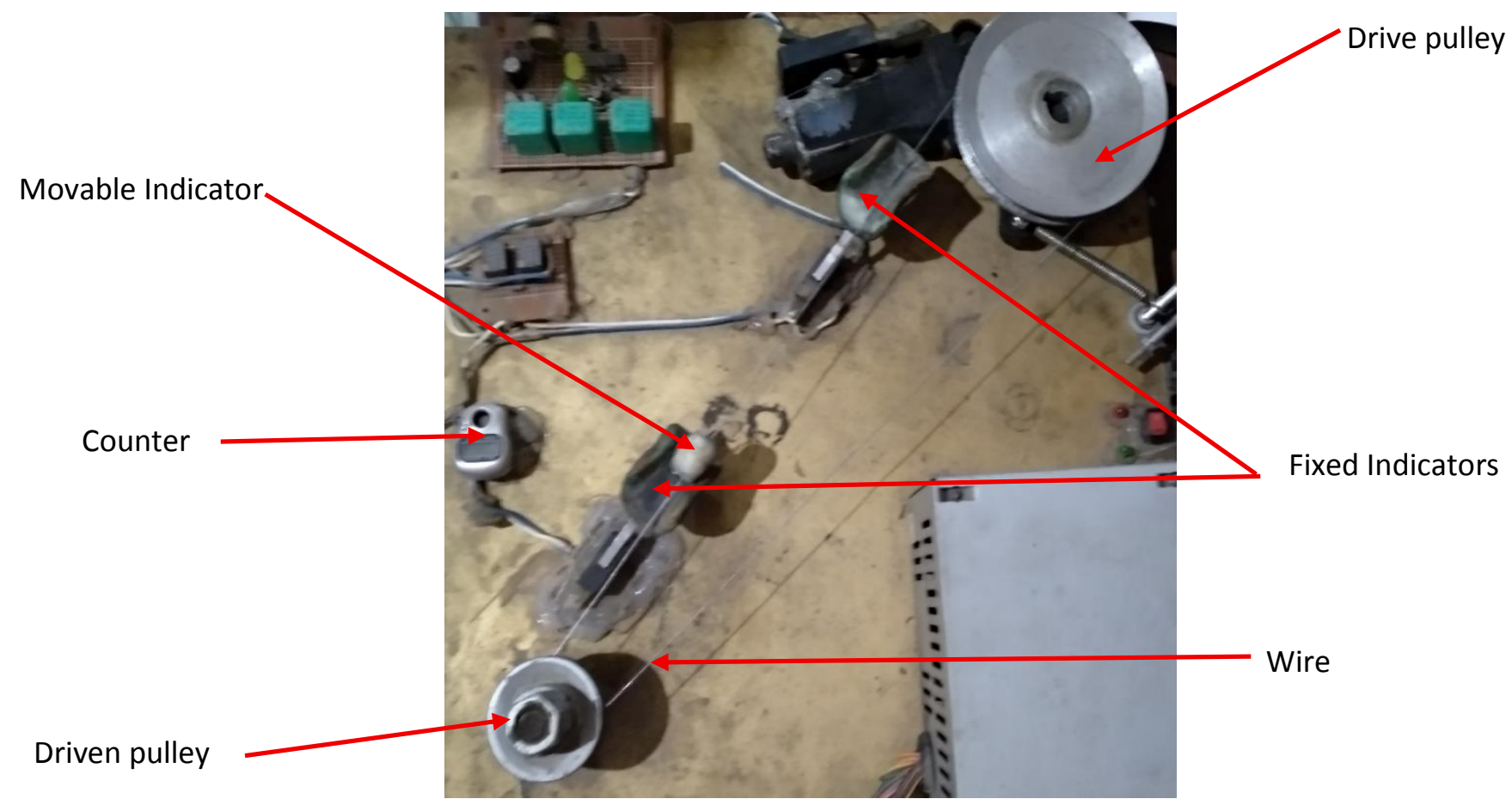

(a) The fatigue test setup.

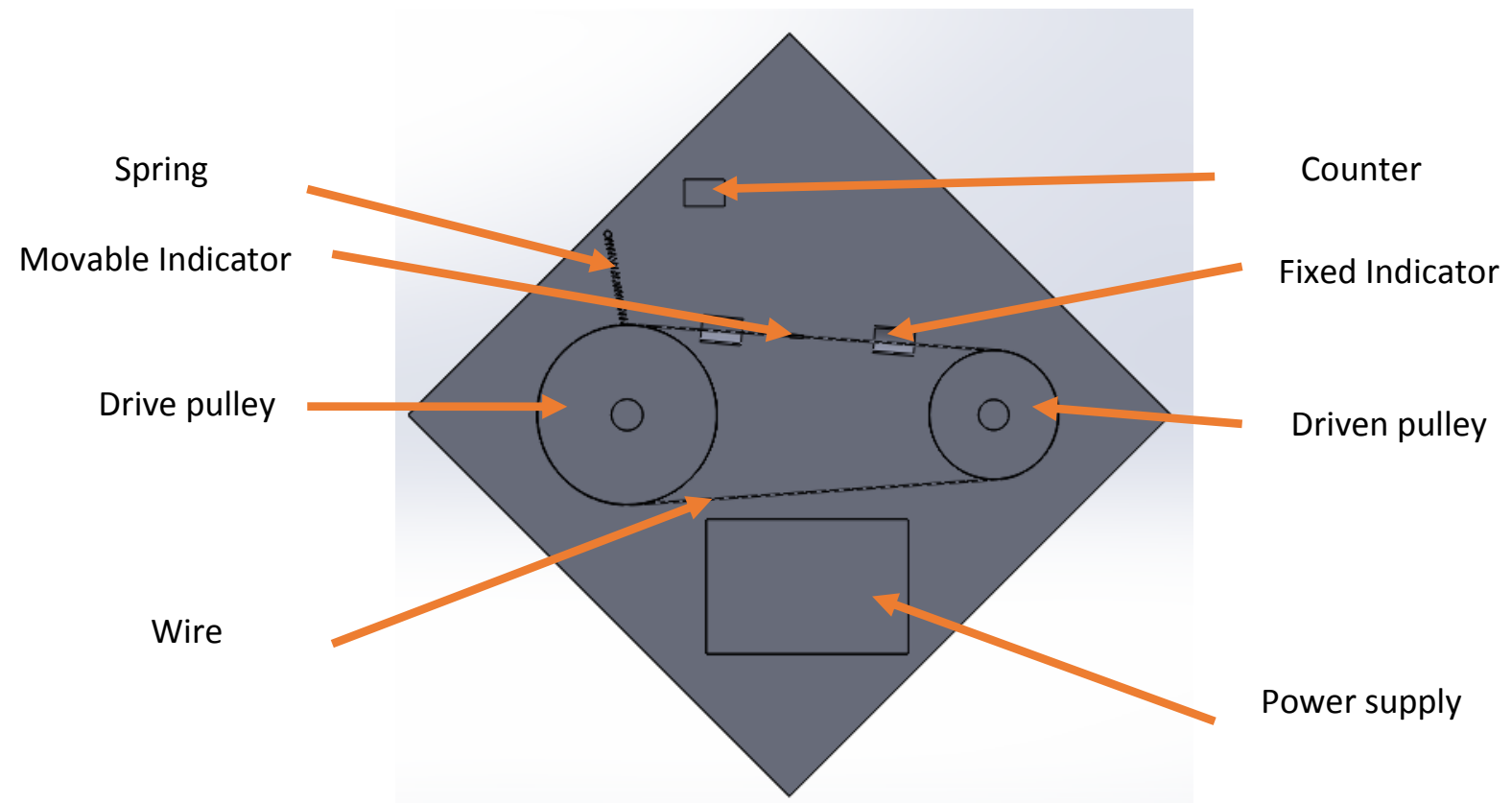

Fig.2. (b) Schematic drawing of the fatigue setup. 
Variable diameters of test pulleys were used to estimate the fatigue life under bending. These diameters were $(75,45, \& 35) \mathrm{mm}$. A steel spring was used to ensure that the wire was under tension all the time during the test. To calculate the spring force; the equation $\mathrm{F}=\mathrm{k} \Delta \mathrm{x}$ was used. Where, $\mathrm{F}$ is the spring force in $\mathrm{N}, \mathrm{k}$ is the spring stiffness in $\mathrm{N} / \mathrm{mm}$, and $\Delta x$ is the extension of the spring in $\mathrm{mm}$. different weights were attached to the spring and the resulted extensions were measured, the spring stiffness was calculated using the previous equation. Then, the spring stiffness and the extension were substituted in the same equation to finally get the spring force.

\section{Finite element analysis}

The finite element simulation was run out using ANSYS WB program, and the model geometry was drawn by SOLID WORKS. The finite element model was run out for two pulley diameters of $35 \mathrm{~mm}$ and $45 \mathrm{~mm}$ only due to the time consumption.

The model was prepared and parameters were set as following. The used material was non-linear structural steel from the ANSYS library as the Tensile yield strength $=2.5^{*} 10^{8} \mathrm{~Pa}$, Young's modulus $=2 * 10^{11} \mathrm{~Pa}$, Strength coefficient $=9.2 * 10^{8} \mathrm{~Pa}$, Strength exponent $=-0.106$, Ductility coefficient $=0.213$, and Ductility exponent $=-0.47$.

Three types of joints were used; rotational joints for the drive and driven pulleys, fixed joint for the machine base, and translational joint for the movable indicator.

Two types of contacts were chosen. Rough contact was used between the wire and the pulleys with the symmetric behavior using pure penalty formulation and the detection method of normal nodal from contact. While bonded contact was used between the movable indicator and the wire.

The chosen meshing type was contact sizing of $2.5 \mathrm{~mm}$ for the two areas of contact between the wire and the pulleys, and the other type of meshing was sweep method of the size of $2.5 \mathrm{~mm}$ for the wire, Figure 3.

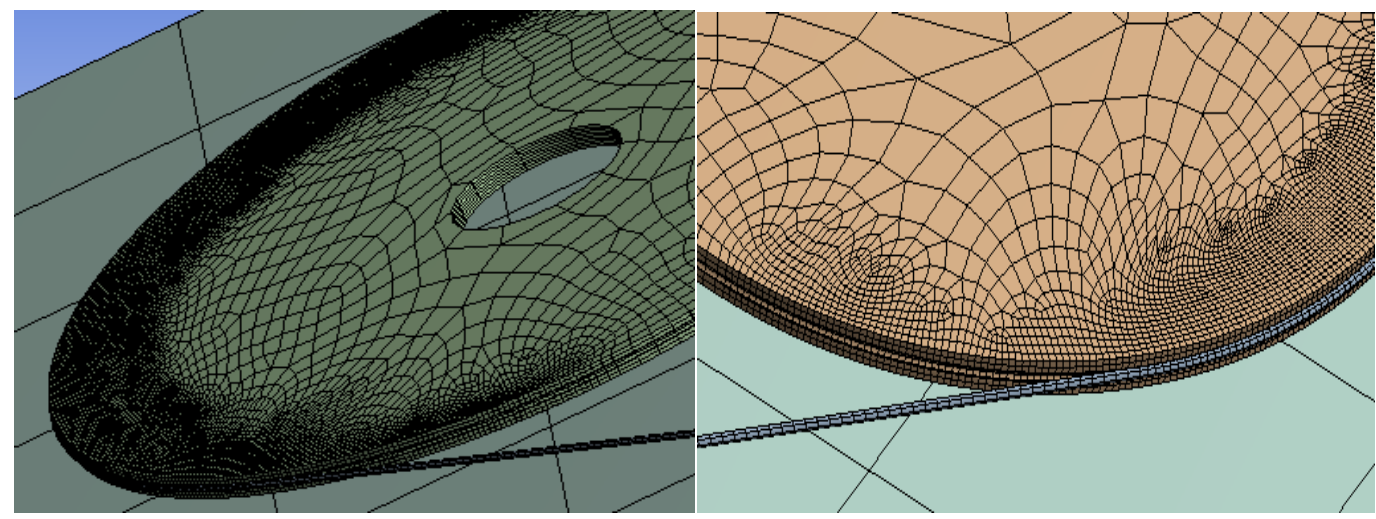

(a)

(b) 


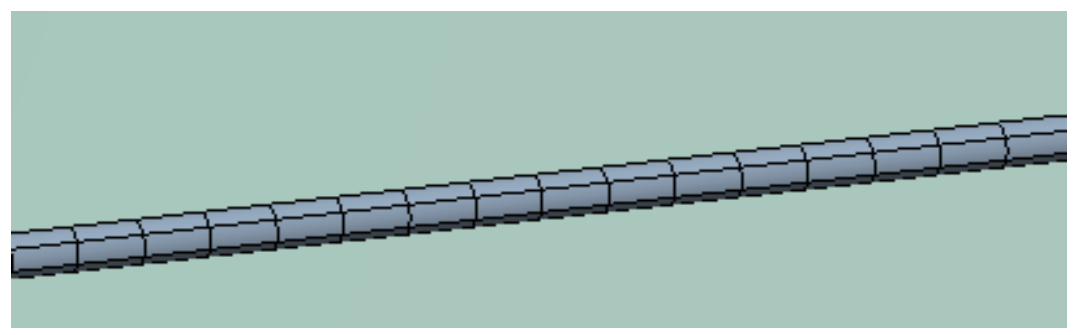

(c)

Fig.3. Element types and sizes of the wire, drive and driven pulleys. Where, (a) Mesh type of the contact between drive pulley and wire, (b) Mesh type of the contact between driven pulley and wire, and (c) Mesh type of the wire.

Table 1 summarizes the number of nodes and elements used in FE modeling in case of 35 and $45 \mathrm{~mm}$ bending diameters.

Table.1. Number of nodes and elements used in FE modeling.

\begin{tabular}{|c|c|c|c|c|c|}
\hline No. & Part name & $\begin{array}{c}\text { Number of nodes } \\
\text { Bending diameter } \\
=35 \mathrm{~mm}\end{array}$ & $\begin{array}{c}\text { Number of nodes } \\
\text { Bending diameter } \\
=45 \mathrm{~mm}\end{array}$ & $\begin{array}{c}\text { Number of } \\
\text { elements } \\
\text { Bending diameter } \\
=35 \mathrm{~mm}\end{array}$ & $\begin{array}{c}\text { Number of } \\
\text { elements } \\
\text { Bending diameter } \\
=45 \mathrm{~mm}\end{array}$ \\
\hline 1 & Wire & 2156 & 2312 & 179 & 192 \\
\hline 2 & Drive pulley & 23524 & 23733 & 4992 & 5034 \\
\hline 3 & Driven pulley & 5378 & 12922 & 1044 & 2676 \\
\hline 3 & Movable indicator & 2280 & 2280 & 360 & 360 \\
\hline 4 & Base plate & 960 & 960 & 121 & 121 \\
\hline 5 & Total & 34298 & 42207 & 6696 & 8383 \\
\hline
\end{tabular}

Force of $28 \mathrm{~N}$ was applied to ensure that the wire is under tension all the time during the test. Constrains were set; the wire motion was controlled to be in $X-Y$ direction only, and not to run away from the pulleys, and the movable indicator was adjusted to move only in $X$ direction, Figure 4 . The chosen fatigue details used in FE model are summarized in Table 2.

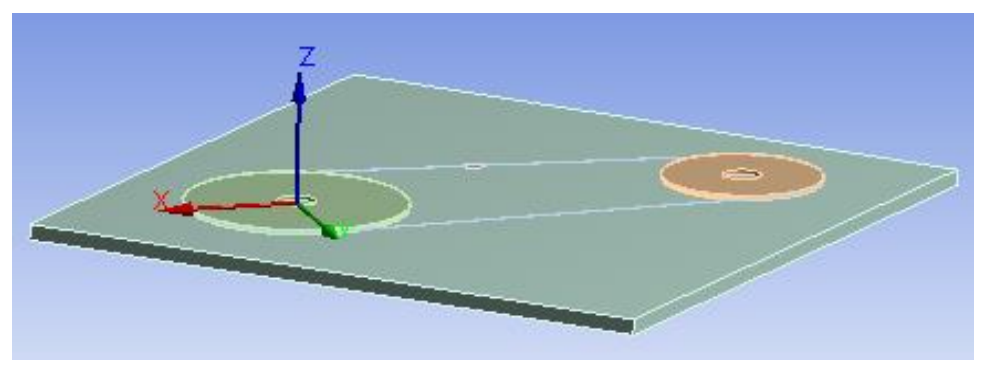

(a) Wire constrain to move in $X-Y$ direction only. 


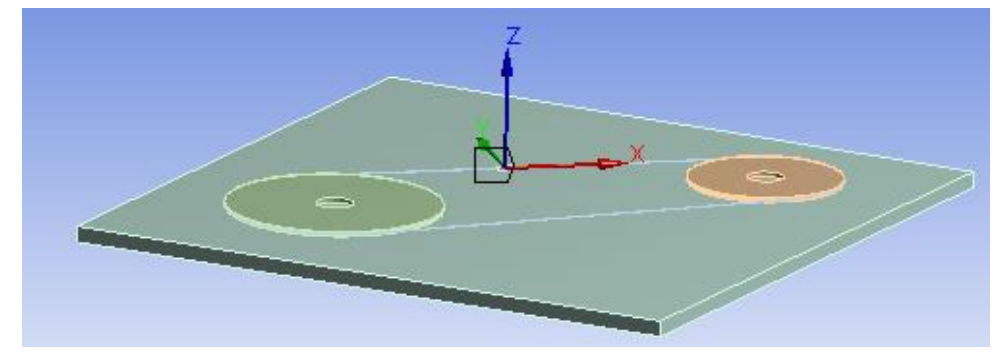

(b) Movable indicator constrain to move in X-direction only.

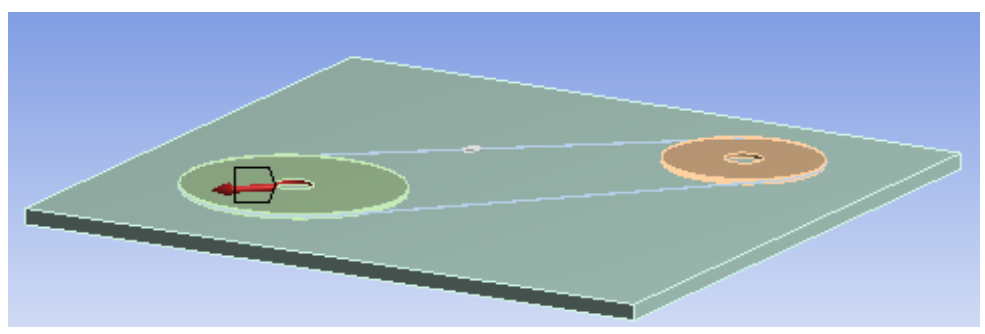

(c) Force direction.

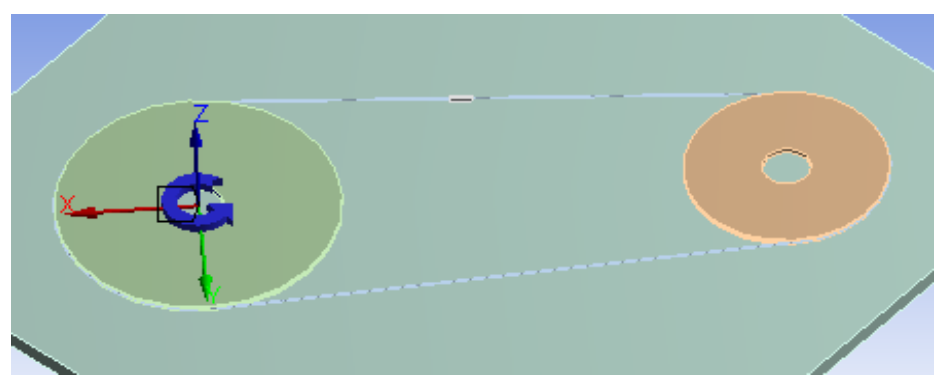

(d) Rotational direction of the drive pulley.

Fig.4. Setting of the model constrains.

Table.2. Fatigue details of the finite element model.

\begin{tabular}{|c|c|}
\hline Fatigue details & value \\
\hline Fatigue strength factor $(\mathrm{kf})$ & 0.78 \\
\hline Type of loading & Fully reversed \\
\hline Display time & End time \\
\hline Analysis type & Strain life \\
\hline Mean stress theory & Morrow \\
\hline Stress component & Max shear \\
\hline
\end{tabular}

\section{Results}

\section{1- Fatigue test}

The strain occurred in wire during fatigue test can be calculated as follow.

$\varepsilon($ Strain $)=\mathrm{d}$ (wire diameter in $\mathrm{mm}) / \mathrm{D}$ (bending diameter in $\mathrm{mm}$ ).

Where the wire diameter is $0.8 \mathrm{~mm}$. 
Table3 summarizes the fatigue test results. Figure 5 represents the relation between strain and fatigue life for tested wire using different pulley diameters.

Table.3. Fatigue life of the tested wire in cycles.

\begin{tabular}{|c|c|c|}
\hline $\begin{array}{l}\text { Bending diameter, } \\
(\mathrm{mm})\end{array}$ & Strain $(\varepsilon)$ & $\begin{array}{c}\mathbf{N}=\text { fatigue life, } \\
\text { cycles }\end{array}$ \\
\hline \multirow{3}{*}{ 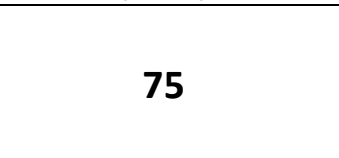 } & \multirow{3}{*}{0.0107} & 13425 \\
\hline & & 14961 \\
\hline & & 16646 \\
\hline \multirow{3}{*}{45} & \multirow{3}{*}{0.018} & 9490 \\
\hline & & 11796 \\
\hline & & 10487 \\
\hline \multirow{3}{*}{35} & \multirow{3}{*}{0.0229} & 4097 \\
\hline & & 4488 \\
\hline & & 4612 \\
\hline
\end{tabular}

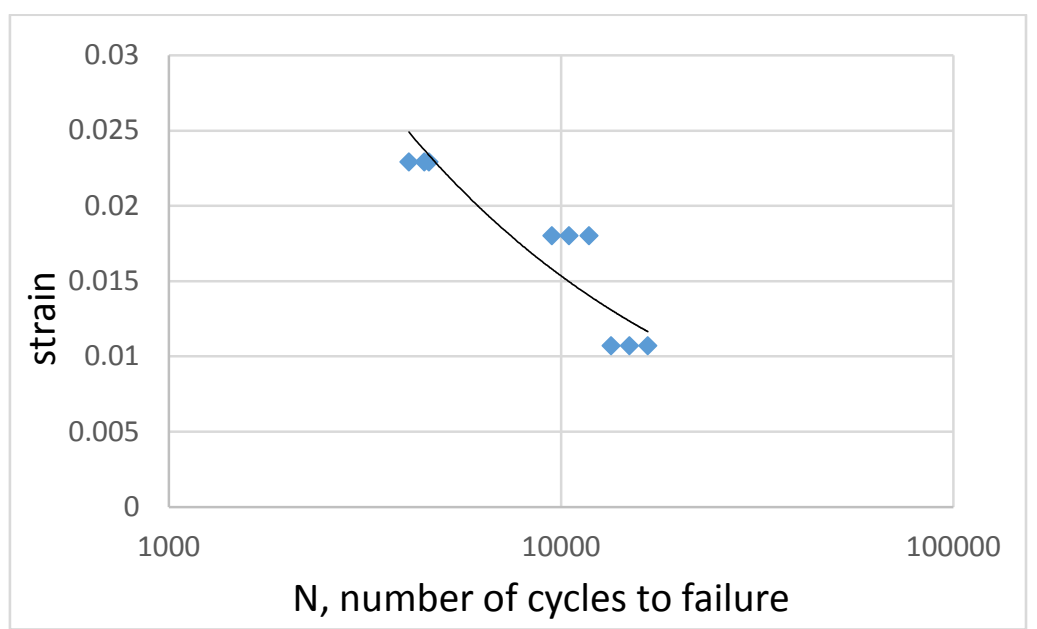

Fig.5. Relationship between fatigue life and strain

\section{2- Finite element analysis results}

\section{Fatigue life}

Table 4, summarizes the fatigue life obtained from FE Modeling for 35, and 45 bending diameters. Table 5, summarizes Von-Mises parameters, such as equivalent stress, equivalent strain, equivalent plastic strain, and total strain obtained from FE modeling for the same bending diameters.

Table.4. fatigue life obtained from the finite element model.

\begin{tabular}{|c|c|}
\hline Diameter $(\mathbf{m m})$ & Fatigue life (cycle) \\
\hline $\mathbf{4 5}$ & 10759 \\
\hline 35 & 4232 \\
\hline
\end{tabular}

Table.5. Von-Mises parameters results. 


\begin{tabular}{|c|c|c|c|c|}
\hline \multirow{2}{*}{ Bending Diameter $(\mathbf{m m})$} & \multicolumn{2}{|c|}{$35 \mathbf{~ m m}$} & \multicolumn{2}{c|}{$\mathbf{4 5} \mathbf{~ m m}$} \\
\cline { 2 - 5 } & Minimum & Maximum & Minimum & Maximum \\
\hline Average Equivalent Stress, MPa & 0.47047 & 417.71 & 0.99736 & 337.9 \\
\hline Equivalent Elastic Strain & $6.8891 \mathrm{e}-005$ & $2.0885 \mathrm{e}-003$ & $9.0784 \mathrm{e}-005$ & $2.0557 \mathrm{e}-003$ \\
\hline Equivalent Plastic Strain, $\mathbf{m m}$ & 0 & $6.7661 \mathrm{e}-002$ & 0 & $6.0595 \mathrm{e}-002$ \\
\hline Equivalent Total Strain, $\mathbf{m m}$ & $6.8891 \mathrm{e}-005$ & $6.9414 \mathrm{e}-002$ & $9.0784 \mathrm{e}-005$ & $6.2288 \mathrm{e}-002$ \\
\hline
\end{tabular}

The results of Von-Mises parameters are shown in Figures (6:9).

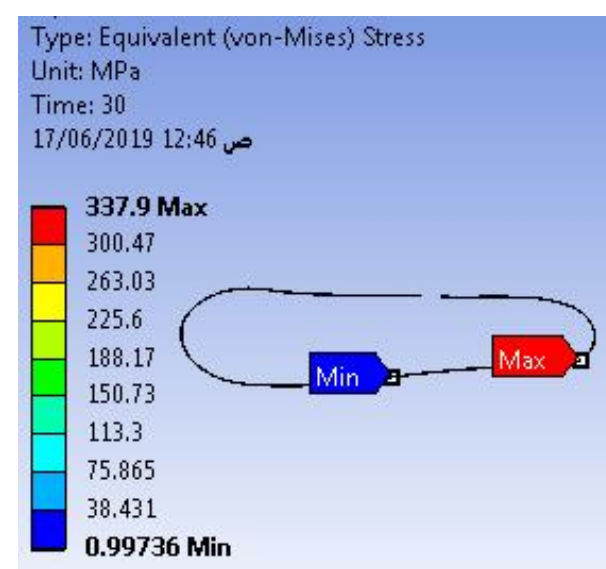

(a) Bending diameter $35 \mathrm{~mm}$.

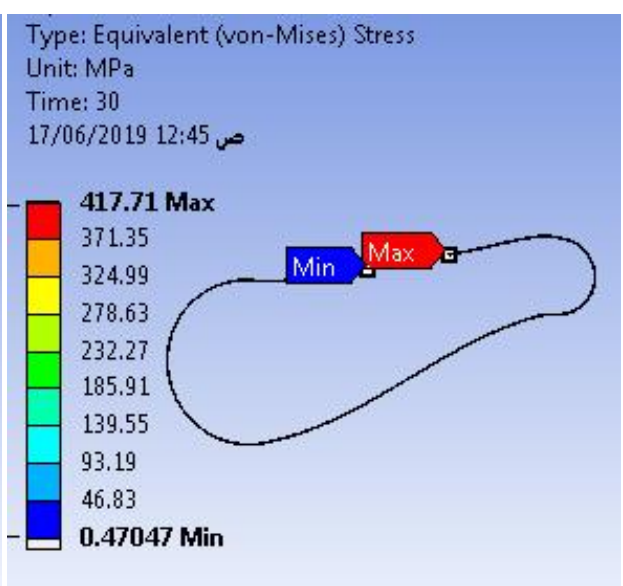

(b) Bending diameter $45 \mathrm{~mm}$.

Fig.6. Equivalent (Von-Mises) Stress

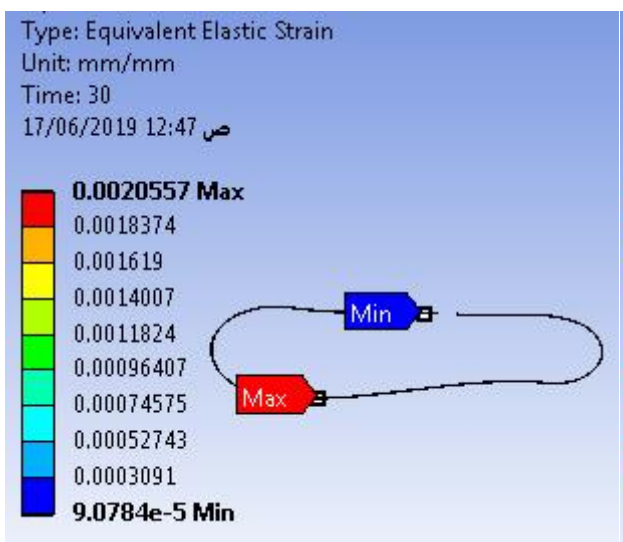

(a) Bending diameter $35 \mathrm{~mm}$.

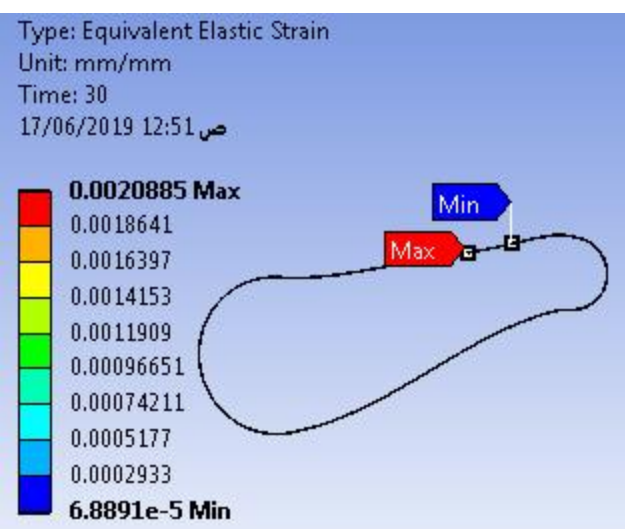

(b) Bending diameter $45 \mathrm{~mm}$.

Fig.7. Equivalent (Von-Mises) elastic strain 


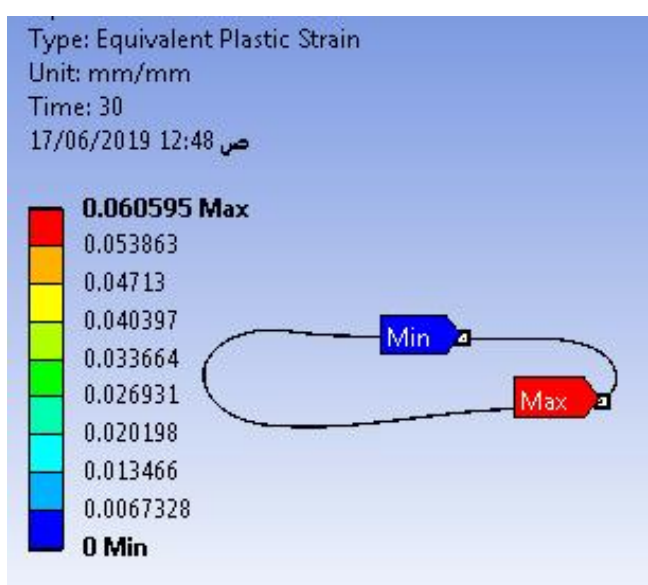

(a) Bending diameter $35 \mathrm{~mm}$.

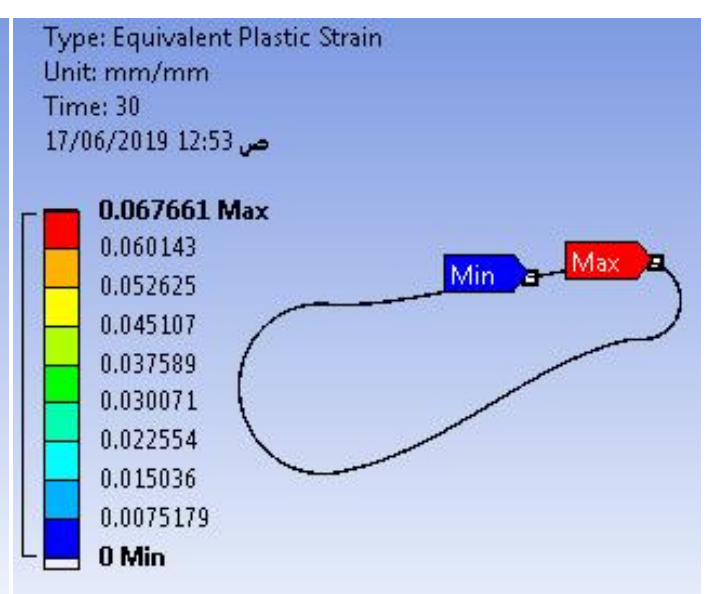

(b) Bending diameter $45 \mathrm{~mm}$.

Fig.8. Equivalent plastic strain

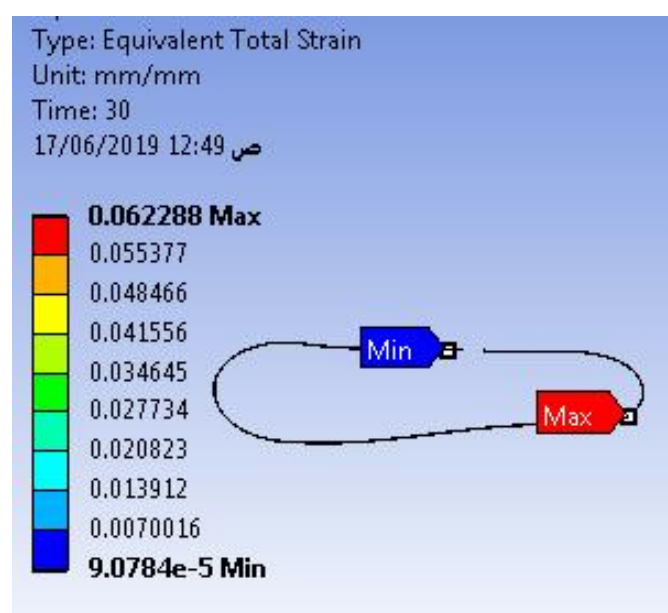

(a) Bending diameter $35 \mathrm{~mm}$.

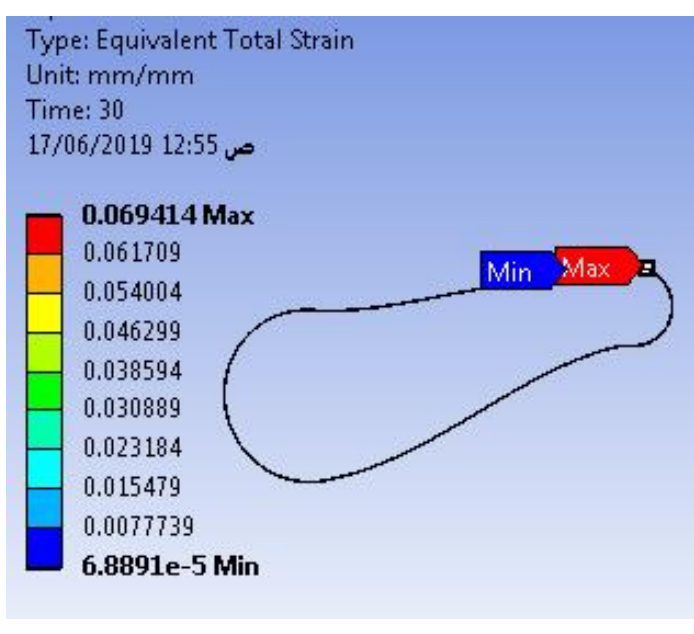

(b) Bending diameter $45 \mathrm{~mm}$.

Fig.9. Equivalent total strain

\section{Discussion}

Table 6 summarizes the comparison between the fatigue life obtained from experimental fatigue tests and from the Finite Element Method. From these results, it can be noticed that the fatigue life values obtained from Finite Element Method are very close to the experiment results with an acceptable $\%$ of deviation.

Table.6. Comparison of experiment and FEM fatigue life results.

\begin{tabular}{|c|c|c|c|c|}
\hline $\begin{array}{c}\text { Diameter, } \\
(\mathbf{m m})\end{array}$ & $\begin{array}{c}\text { Average Fatigue Life (Cycle) } \\
\text { Experiment }\end{array}$ & $\begin{array}{c}\text { Fatigue Life (Cycle) } \\
\text { FEM }\end{array}$ & Difference & Deviation\% \\
\hline $\mathbf{4 5}$ & 10591 & 10322 & 269 & 2.5415 \\
\hline $\mathbf{3 5}$ & 4399 & 4232 & 167 & 3.7936 \\
\hline
\end{tabular}




\section{Conclusion}

Fatigue life of steel wire has been studied using FEM by ANSYS program as well as conducting fatigue tests using fatigue setup.

From the results obtained from this work, the following conclusions can be drawn.

1- Fatigue test setup has been designed and constructed in order to conduct experimental fatigue tests for steel wire.

2- Fatigue setup has been used successfully to obtain the fatigue life of steel wire using different pulley diameter of 35,45 , and $75 \mathrm{~mm}$.

3- Using smaller bending diameter achieved a higher values of Von-Mises equivalent stress, equivalent strain, equivalent plastic strain, and total strain.

4- Using smaller bending diameter resulting in reducing the fatigue life due to increasing the bending strain and bending stress.

5- The results obtained from Finite Element model were in a good agreement with the experimental results with an acceptable \% of deviation.

\section{References}

[1] Jay C. Martin, "Strands That Stand: Using Wire Rope to Date and Identify Archaeological Sites", The International Journal of Nautical Archaeology, (2014), 43.1: 151-16

[2] Yusuf Aytac Onur, C Erdem Imrak, "Experimental and Theoretical Investigation of Bending Over Sheave Fatigue Life of Stranded Steel Wire Rope", Indian Journal of Engineering \& Materials Sciences Volume. 19, June 2012, 189-195.

[3] Juan Felipe Beltrána, Enzo De Vico, "Assessment of Static Rope Behavior with Asymmetric Damage Distribution", Engineering Structures, 2015, 84-98.

[4] Juan $\mathrm{Wu}$, "The finite element modeling of spiral ropes", Int. J Coal Sci. Technol., (2014), 1(3):346-355.

[5] Gerdemeli I., Kurt S., Anıl A.S, "Analysis with Finite Element Method of Wire Rope", Faculty of Mechanical Engineering Istanbul Technical University Turkey, 2012.

[6] Sung-Yun Kima, b, Phill-Seung Lee, "Modeling of Helically Stranded Cables Using Multiple Beam Finite Elements and Its Application to Torque Balance Design", Construction and Building Materials, 2017, 591-606.

[7] Sung Ho Kim, Rjeon Hwan Bae, Jae Do Kwon, "Bending Fatigue Characteristics of Wire Rope", Journal of Mechanical Science and Technology 26, 2012, 2107-2110.

[8] Robert Basana, Domagoj Rubešab, Marina Franuloviüa, Božidar Križan, "A Novel Approach to the Estimation of Strain Life Fatigue Parameters", Procedia Engineering, 2010, 417-426.

[9] Najaf Hussain, Masri Bin Baharom, and Mui'nuddin Maharun, "Analysis of Optimum Wire Rope Configuration for Equal Unidirectional Torsional 
Stiffness for Flexible Steering Shaft", proceeding of MATEC Web of Conferences 74, 2016.

[10] Zhu Hui-ling, Zhu Xin-yin, Wang Yu-lin, "Numerical Analysis of Sliding Friction Coefficient and The Normal Pressure between the Cable Wire", International Journal on smart sensing and intelligent systems, volume. 7, NO. 4, DECEMBER 2014.

[11] M. Fraldi, G. Perrella, M. Ciervo, F. Bosia, N.M. Pugno, "A hybrid deterministic-probabilistic approach to model the mechanical response of helically arranged hierarchical strands", Journal of Mechanics and physics of solids. May, 2017, 338-352.

[12] Erdogan Madenci, Ibrahim Guven, "The Finite Element Method and Applications in Engineering Using ANSYS", Second Edition, Springer International Publishing, 2015. 